\section{Ramsay Hunt Syndrome}

Sir,

Ramsay Hunt Syndrome (RHS), also termed as Hunt's Syndrome and herpes zoster oticus, was first described by James Ramsay Hunt in $1907 .{ }^{1}$ It is a rare neurological syndrome caused by varicella zoster virus. RHS has unilateral facial weakness and painful blisters in the ear canal leading to auditory loss and vestibular symptoms. It occurs due to reactivation of herpes zoster virus that has previously caused the infection. It is a rare complication of primary varicella zoster infection. Unilateral facial paralysis, otalgia, and vesicular rash of external auditory canal constitute the main triad of the disease. The vestibulocochlear nerve is most commonly involved nerve. ${ }^{2}$

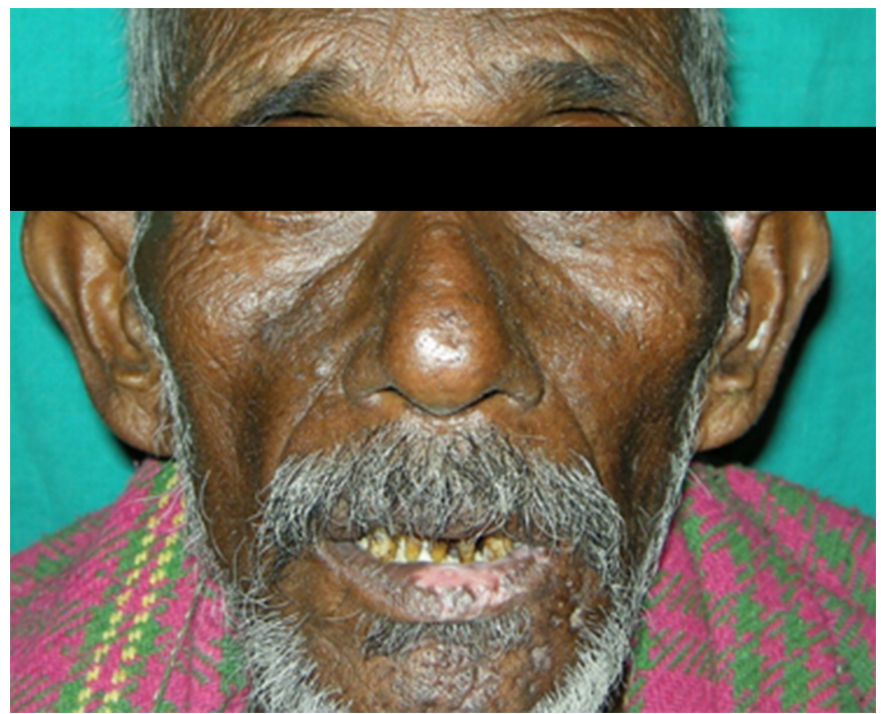

Figure 1: The left side of the face shows multiple blisters and ulcers.

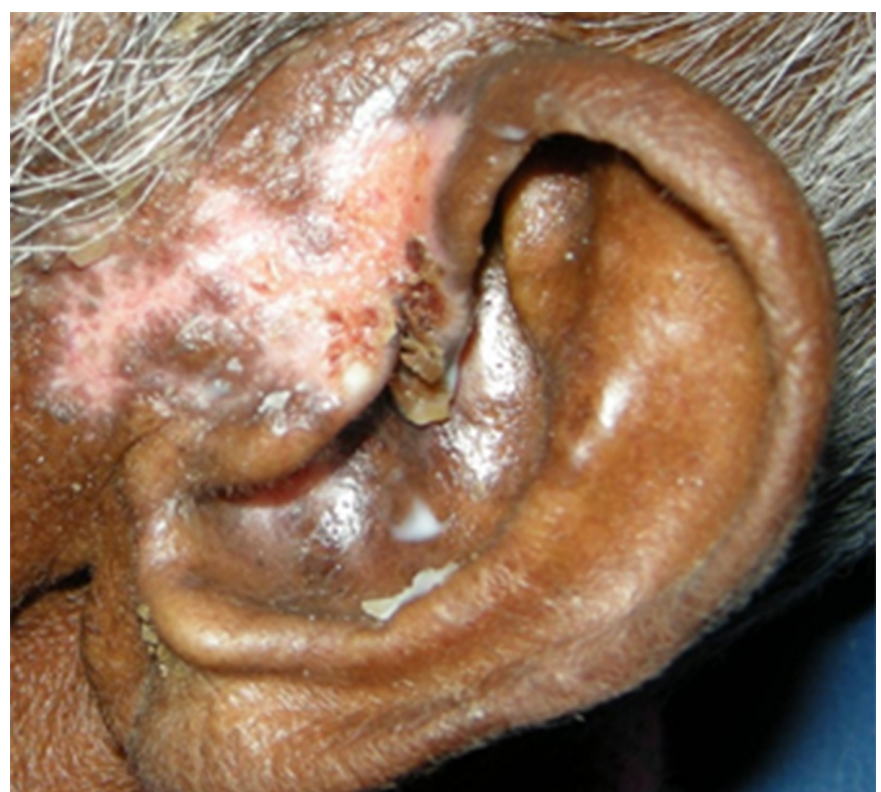

Figure 2: The area of the left ear shows vesicular rash around auricular region.

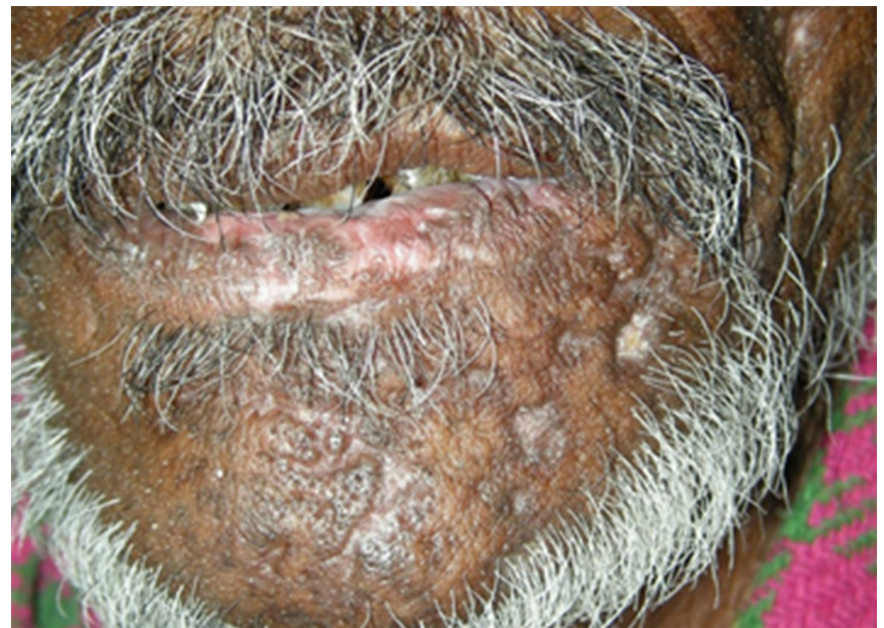

Figure 3: The lower lips and lower part of the face show painful blisters.

A 62-year male came to the Department of Oral Medicine and Radiology with a chief complain of multiple blisters and ulcers in left side of the face, chin and ear (Figure 1). He had reduced hearing and taste sensation along with vesicular eruptions, which ruptured and became ulcerated in appearance. There was no relevant medical history and no deleterious habits. Clinical examination revealed a vesicular rash around auricular region of the left ear (Figure 2). The pain was described as burning sensation around left ear. Painful blisters were present not only on left external ear and external auditory canal, but also involved lower lips and lower part of face on left side (Figure 3). Due to involvement of vestibulocochlear nerve, patient had vertigo, sensorineural hearing loss, and tinnitus. Intraoral examination showed poor oral hygiene with periodontitis. Based on a detailed patient history, thorough clinical evaluation and identification of characteristic symptoms, it was diagnosed as RHS. Early diagnosis and treatment with combination of acyclovir and corticosteroids improved the condition. Acyclovir, 10 $\mathrm{mg} / \mathrm{kg} /$ day, and prednisolone, $1 \mathrm{mg} / \mathrm{kg} /$ day, were advised for 7 days.

RHS is characterised by cutaneous lesions of external auditory canal with involvement of the ipsilateral facial and auditory nerves. RHS is cause by reactivation of the varicella zoster virus withinthesensory ganglion of the facial nerve. As vestibulocochlear nerve lies near the sensory ganglion of the facial nerve within the facial canal, both the nerves are affected. This leads to facial paralysis along with hearing deficits, vertigo, and other auditory and vestibular symptoms. Patients may develop loss of taste mainly in anterior two-thirds of the tongue. Most of these neuralgias resolve within 1 year. Symptoms may also include vomiting, hearing loss, hyperacusis, tinnitus, eye pain and lacrimation.

Corticosteroids and acyclovir are main line of treatment of RMS. Supportive therapy includes non-aspirin antipyretics. Antiviral drugs reduce mucocutaneous lesions, which promotes healing after one week. Carbamazepine can be used as a vestibular suppressant to alleviate the symptoms. ${ }^{3}$ Follow-up should be 
done at an interval of 2 weeks, 6 weeks and 3 months. Complications include development of post-herpetic neuralgia, unresolved facial paralysis and herpes zoster encephalitis. ${ }^{4}$ Patients with no hypertension and diabetes have higher chances of complete recovery. ${ }^{5}$ Early diagnosis and treatment are important for improvement of the involved nerves' function.

\section{PATIENT'S CONSENT:}

Informed consent was obtained from the patient to publish the data concerning this case.

\section{CONFLICT OF INTEREST:}

The author declared no conflict of interest.

\section{AUTHOR'S CONTRIBUTION:}

SS: Contributed to the conception of the work, collected the patient data and images and participated in literature review and authored the full manuscript.

\section{REFERENCES}

1. Hunt JR. On herpetic inflammation of the geniculate ganglion. A new syndrome and its complications. J Nerv Ment Dis 1907; 34:73-96.

2. Wagner $G$, Klinge $H$, Sachse MM. Ramsay Hunt syndrome. J Dtsch Dermatol Ges 2012; 10:238-244. doi.org/10.1111/ j.1610-0387.2012.07894.x.
3. Da Costa Monsanto R, Bittencourt AG, Neto NJ, Beilke SC, Lorenzetti FT, Salomone R. Treatment and prognosis of facial palsy on ramsay hunt syndrome: Results based on a review of the literature. Int Archives Otorhinolaryngol 2016; 20(04):394-400. doi: 10.1055/s-0036-1584267.

4. Eskiizmir G, Uz U, Taskiran E, Unlü H. Herpes zoster oticus associated with varicella zoster virus encephalitis. Laryngoscope 2009; 119(4):628-30. doi: 10.1002/lary. 20111.

5. Yeo SW, Lee DH, Jun BC, Chang KH, Park YS. Analysis of prognostic factors in Bell's palsy and Ramsay Hunt syndrome. Auris Nasus Larynx 2007; 34(2):159-64. doi: 10.1016/j.anl.2006.09.005.

\section{Suman Sen}

Department of Oral Medicine and Radiology, Haldia Institute of Dental Sciences and Research, India

Correspondence to: Dr. Suman Sen, Department of Oral Medicine and Radiology, Haldia Institute of Dental Sciences and Research, India

E-mail: dentalclinicip@gmail.com

Received: May 18, 2020; Revised: June 28, 2020;

Accepted: July 03, 2020

DOI: https://doi.org/10.29271/jcpsp.2021.05.610 